\title{
Considerations for Applying Six Strategies for Effective Learning to Instruction
}

\author{
Cynthia Nebel ${ }^{1}$ (D)
}

Accepted: 21 September 2020 / Published online: 30 September 2020

(C) International Association of Medical Science Educators 2020

Cognitive psychologists study memory, attention, and perception. By gaining an understanding of these basic processes, we are able to develop teaching and learning strategies that maximize knowledge retention and transfer. After decades of research, cognitive psychologists have identified six strategies with considerable experimental evidence to support their use [9]. These six strategies include spaced practice, interleaving, elaboration, concrete examples, dual coding, and retrieval practice. Below I describe each of these strategies but also caution the reader to consider how any particular strategy is utilized in a learning activity. The key to effective learning is understanding the underlying mechanism-understanding how the learner is mentally engaged in the learning process.

The first of the six strategies is spaced practice. Spaced practice is a strategy in which study sessions are separated in time instead of being massed into a single session [1]. For example, long-term retention will be improved if a student studied for one hour every night of the week instead of seven hours the night before an exam. Interleaving often involves some amount of natural spacing, but adds an additional benefit from changing the order in which items are studied or reviewed [8]. In this way, students are more likely to recognize the similarities and differences between items or materials. Elaboration, or more specifically elaborative interrogation, involves asking "how" and "why" questions about materials [7]. This works particularly well when students can connect the elaborated information to their prior knowledge and therefore doesn't work as well for novices [10]. A strategy that does work well with novices is the use of concrete examples, in which students are given a variety of examples using concrete information that is easier to understand and

Cynthia Nebel

cynthia.nebel@vanderbilt.edu

1 Peabody College, Vanderbilt University, Nashville, TN, USA visualize than the abstract counterparts [2]. Dual coding is a strategy in which verbal and visual information are combined to enhance encoding [6]. That is, pictures, graphic organizers, diagrams, etc. can be effectively used in combination with verbal information. Finally, retrieval practice increases retention over and above repeated studying of information.

While these six strategies have been identified as effective for learning, the manner in which they are applied does matter. As noted above, elaboration is a strategy that works more effectively with relative experts, as students need background information to elaborate on. Dual coding is useful, but if the visual and verbal information is redundant, then learning is hampered [3]. Several studies have demonstrated that the manner in which you apply retrieval practice is important for learning. In one study, elementary students were given a retrieval activity that was identical (but with age-appropriate materials) to one that had been previously used with college students [4]. The elementary students performed near floor on the task and needed scaffolded support in order to show a retrieval benefit. In another study, off the shelf materials were used in a manner consistent with how instructors use quizzing in the classroom [11]. While the assumption with these materials was that retrieval of factual information should promote transfer, there was no increase in performance on related application questions, likely due to the degree or relatedness between items. Similarly, in an unpublished study, having students write their own retrieval practice questions and then answer a partner's question (that is, peer quizzing) actually led to reduced performance on the related unit exam [5]. The questions that the students wrote were more item-specific than the instructorwritten quiz questions, leading students to attend to surfacelevel material more in the student-written condition.

In order to appropriately apply evidence-based practices, it is key for instructors to understand the underlying mechanisms that support their use. The strategies for effective learning summarized above should serve as guiding principles, such that instructors are better able to apply the science of learning to the art of teaching. Each strategy can and should 
be used with consideration of the materials, students, background knowledge, and current context instead of using a onesize-fits-all approach to these activities. With thoughtful application, these evidence-based learning strategies have the potential to improve benefits from individual study as well as classroom instruction.

\section{Compliance with Ethical Standards}

Conflict of Interest The author declares that there is no conflict of interest.

Ethical Approval NA

Informed Consent NA

\section{References}

1. Carpenter SK, Cepeda NJ, Rohrer D, Kang SH, Pashler H. Using spacing to enhance diverse forms of learning: review of recent research and implications for instruction. Educ Psychol Rev. 2012;24(3):369-78.

2. Gick ML, Holyoak KJ. Schema induction and analogical transfer. Cogn Psychol. 1983;15:1-38.
3. Kalyuga S, Chandler P, Sweller J. Managing split-attention and redundancy in multimedia instruction. Appl Cognit Psychol. 1999;13(4):351-71.

4. Karpicke JD, Blunt JR, Smith MA, Karpicke SS. Retrieval-based learning: the need for guided retrieval in elementary school children. J Appl Res Memory Cognit. 2014;3(3):198-206.

5. Nebel CL, Joy E, Stran B, Hallauer C (2020) Student self-quizzing: laboratory to classroom translations. Unpublished manuscript.

6. Paivio A (1971) Imagery and language. In Imagery (pp. 7-32). Academic Press.

7. Pressley M, Symons S, McDaniel MA, Snyder BL, Turnure JE. Elaborative interrogation facilitates acquisition of confusing facts. J Educ Psychol. 1988;80(3):268-78.

8. Taylor K, Rohrer D. The effects of interleaved practice. Appl Cogn Psychol. 2010;24(6):837-48.

9. Weinstein Y, Sumeracki M, Caviglioli O. Understanding how we learn: a visual guide: Routledge; 2018.

10. Woloshyn VE, Pressley M, Schneider W. Elaborative-interrogation and prior-knowledge effects on learning of facts. J Educ Psychol. 1992;84(1):115-24.

11. Wooldridge CL, Bugg JM, McDaniel MA, Liu Y. The testing effect with authentic educational materials: a cautionary note. J Appl Res Memory Cognit. 2014;3(3):214-21.

Publisher's Note Springer Nature remains neutral with regard to jurisdictional claims in published maps and institutional affiliations. 